\title{
Autonomia e cidadania na reabilitação psicossocial: uma reflexão
}

\author{
Autonomy and citizenship in psychosocial rehabilitation: a reflection
}

AliceH irdes ${ }^{1}$

\footnotetext{
${ }^{1}$ Universidade Luterana do

Brasil, Unidade

Universitária de Gravataí.

Av. Itacolomi 3.600, São

Vicente. 94170-240

Gravataí RS.

alicehirdes@gmail.com
}

\begin{abstract}
This article approaches autonomy and citizenship in the psychosocial rehabilitation process. The bibliographical review approaches concepts such as de-institutionalization and rehabilitation used by authors following the tradition of Basaglia, as well as American and British authors discussing thequestion rehabilitation/work/mental health. The results show that while the first are adopting a more flexible style, in which production of life is more important that productive life, American and British authors present models whose objective is the normalization of psychiatric patients by confronting them with the labor market. Both models bring along determinant variables - stigma, expectations, intolerance - denouncing forms of social exclusion from work for marginalized segments of the population. It is concluded that one of the biggest obstacles for rehabilitation is the inclusion in the formal labor market due to its competitiveness and to the need for a new perspective of the relation of mental health and society.

Key words M ental health, Activities of daily living, Personal autonomy
\end{abstract}

Resumo Este artigo aborda a autonomia ecidadania no processo de reabilitação psicossocial. A revisão bibliográfica aborda conceitos de desinstitucionalização e reabilitação de autores da tradição basagliana, assim como autores americanos e ingleses que discutem a questão da reabilitação/trabalho/ saúdemental. O sresultados apontam queenquanto os primeiros adotam um estilo de trabalho maisfle xível, em queo sentido de produção de vida supera a vida produtiva, os autoresingleseseamericanos apresentam model os em que o objetivo éa normalização dos pacientes psiquiátricos através dos confrontos com o mercado de trabalho. O bserva-se que ambos os model os trazem consigo variáveis determinantes - o estigma, as expectativas, a intolerância -, que denunciam formas de exclusão social do trabalho para segmentos marginalizados da população. Conclui-se queum dos maiores obstáculos diz respei to à inserção no mercado de trabalho formal, em razão da competitividade e da necessidade do estabelecimento de uma nova perspectiva na relação doença mental e sociedade.

Palavras-chave Saúdemental, A tividades cotidianas, Autonomia pessoal 


\section{Introdução}

Na prática, desde 0 advento das discussões sobre desinstitucionalização, muito se tem falado sobre reabilitação psicossocial. Via de regra, os serviços que trabal ham na perspectiva da reforma psiquiátrica intitulam-se reabilitadores. Os princípios, objetivos e pressupostos da reforma psiquiátrica orientam as práticas nos serviços. Da mesma maneira, existem princípios, objetivos e valores que orientam o trabalho de reabilitação psicossocial. Da observância destes, aparentemente fáceis num primeiro olhar, revelar-se-á a concretude das ações dos trabalhadores em saúde mental.

Para Rotelli ${ }^{1}$, a base da instituição inventada a partir dos projetos de desinstitucionalização reside na ruptura da causalidade linear doença-cura, problema-solução e na reconstrução do objeto enquanto sujeito histórico. 0 autor ressalta que as novas instituições deverão estar à altura da complexidade da tarefa de intervir na sua existência sofrimento, remetendo ao processo da constante reconstrução deste sujeito. N estes novos serviços, "o que se convencionou chamar de 'Cultura de Avaliação' tem que estar presente o tempo todo para que nós não nos percamos em linguagem, em saberes, em práticas ou em modelos que não são bem aquilo que se propõe"2. A única forma, segundo este autor, que temos para controlar esta derrapagem é a preocupação com a qualidade.

No Brasil, as práticas desenvolvidas nos serviços superam a produção científica na área. Não podemos simplesmente importar um modelo anglo-saxão (eqüidistante da realidade, pragmático) ou italiano (mais próximo em termos de estilo de trabalho), temos que construir um referencial balizador próprio. Para Silva Filho ${ }^{3}$, a reabilitação no Brasil e em outras partes da América Latina teve o foco compulsivo no trabalho desempregado, sobretudo, na construção e na restituição dos direitos humanos dos portadores de doenças mentais.

0 modelo anglo-saxão de reabilitação vocacional (vocational rehabilitation) e o modelo francês de readaptação (readaptation) representam modelos em que o objetivo é o da normalização dos pacientes psiquiátricos desabilitados através dos confrontos com o mercado de trabalho. E a sua reinserção, segundo uma lógica pragmática, na qual as expectativas não devem ser nem altas e nem baixas demais ${ }^{4}$. 0 autor menciona as dificuldades de interação social como os maiores obstáculos nesse tipo de intervenções. Além dessa, descreve as dificuldades dos programas: em al guns, 0 que é denominado reabilitação é na realidade entretenimento; e a não-preparação dos ambientes para receber pessoas desabilitadas - 0 estigma associado à doença mental. Faz uma crítica a estes modelos de reabilitação por não estar claro o sentido que é atribuído ao trabalho nesse processo se entretenimento, adestramento ou reinserção. Estabelece uma analogia entre programas de social skills training (treinamento de habilidades sociais) e programas de reabilitação laborativa: enquanto no primeiro são apresentadas dificuldades quanto à aplicação das habilidades adquiridas fora do setting, o segundo apresenta uma distância entre os serviços e o mundo externo.

\section{Sociedade, trabal ho e loucura}

A inserção social do homem no mundo do trabaIho se constitui quase naúnica possibilidade de ser aceito, amado e compreendido em nossa sociedade. A modernidadeexclui um contingentecadavez maior, expondo a precariedade de laços, a vulnerabilidade às agressões, a segregação e exclusão. Denuncia que as formas de inclusão social pelo trabalho não são e não estão disponíveis e nem flexíveis para as diferentes necessidades individuais e coletivas dos homens ${ }^{5}$.

Demo ${ }^{6}$, ao abordar os dilemas que o neoliberalismo impõe, analisa que o principal dilema consiste na incapacidade de a cidadania ser posta acima das relações de mercado. Visualiza o mercado como de absoluta relevância. Porém, situa que o dilema advém de as relações de mercado situaremsecomo fim, enão como meio, estabelecendo uma ordem de inversão de valores humanos e éticos. Outro dilema, segundo o autor, reflete a tendência para gerar empregos. Explica que há uma inversão entre investimento em conhecimento e postos de trabalho, estabelecida pela competitividade. Comenta as mutações estruturais pelas quais o trabalho passa, de força de trabalho, num contexto de mais-valia, para inteligência do trabalho. 0 capitalismo competitivo transformou o trabalho em conhecimento inovador. Dessa forma, o "saber fazer" passa a transcender o "fazer".

Para Demo ${ }^{6}$, uma das mais importantes conquistas do final do século diz respeito ao reconhecimento da cidadania como o componente fundamental do desenvolvimento, ficando reservada ao mercado a função indispensável de meio. Salienta que composição de mercado e cidadania constituem um desafio e também um dilema, sobretudo numa sociedade capitalista. 0 autor pontua que cidadania e economia são colunas mestras do desenvolvimento; enquanto uma éfim, outra émeio. 0 processo de desenvolvimento denominado pela Organização das Nações Unidas ( ONU) de huma- 
no e sustentável traz conquistas como a percepção estratégica, que resulta da integração entre o social e o econômico; o predomínio dos fins sobre os meios; a prioridade estratégica para educação e conhecimento ea promoção do bem- estar comum e dos direitos humanos. Coloca a cidadania na raiz dos direitos humanos e da emancipação das pessoas, refletindo o progresso democrático possível.

A centralização decorredo reconhecimento consensual de que o desenvolvimento não se restringe à questão do mercado, ainda que seja meio indispensável, mas considera os fins comuns da sociedade, como qualidade de vida, eqüidade e justiça social. Avanços decorrem destas propostas, no momento em que são reintegrados meios econômicos e fins sociais. Ressalto que cidadania e economia não podem ser visualizadas de maneira separada, ambas são colunas mestras do desenvolvimento, a cidadania remetendo ao fim, enquanto a produção é meio ${ }^{6}$. 0 autor alerta, porém, que não se pode reduzir desenvolvimento à cidadania. Entende que o desafio e dilema das sociedades capitalistas consistem em compor mercado e cidadania.

0 autor traz as conceituações de cidadania tutelada, assistida e emancipada. A cidadania tutelada é a decorrente do clientelismo e paternalismo, cultivada pela elite econômica e política de direita como dádiva ou uma concessão de cima. Este tipo de cidadania se configura como resultado, na reprodução histórica da mesma elite, através da negação/repressão. A cidadania assistida expressa um relativo conhecimento político, o do direito à assistência. Esta também trabalha na reprodução da pobreza política, ao não secomprometer em equalizar as oportunidades, identificada com correntes de esquerda. Nesse caso, temos a população atre lada ao sistema de benefícios estatais. Enquanto a cidadania emancipada remete à condição de, através da competência, fazer-se sujeito histórico e assumir a condução do destino. N esse processo, está implicada a superação da pobreza política, que capacitará à superação da pobreza material. 0 autor lembra que não há emancipação que não perpasse pelas relações de mercado. Entretanto, na cidadania emancipada, o mercado se situa como um instrumento e a cidadania, como um fim ${ }^{6}$.

O binômio trabalho e saúde/doença mental é supersimplificado e idealizado, respectivamente, porque não são considerados os amplos contextos nos quais o trabalho ocorre no que tange aos aspectos social, pessoal e econômico; e idealizado porque nega as contradições que emergem deste contexto ${ }^{7}$. 0 autor situa variáveis determinantes, quais sejam: a exploração e a inflexibilidade na organização do trabalho no que concerne ao contex- to econômico; às expectativas, o estigma eà intolerância em relação ao contexto social e à valorização que o trabal ho traz no que diz respeito ao contexto pessoal.

0 processo de desinstitucionalização, a avaliação crítica da ergoterapia e a crise do welfare se constituem como elementos de análise dos fenômenos sociais e políticos que apresentam conexão com a assistência psiquiátrica. Destaca dentre esses a desinstitucionalização como a que possi bilita a recuperação da contratualidade, ou seja, através das trocas sociais, a obtenção da cidadania social. Entende que da ergoterapia manicomial às coope rativas fora do manicômio foram construídos saberes e práticas que permitiram a compreensão dos mecanismos anti-institucionais do trabalho. $\checkmark$ isualiza as cooperativas como lugares de promoção da autonomia e de proteção, características que deveriam ser próprias de um bom serviço de saúde mental ${ }^{4}$.

De acordo com 0 autor ${ }^{4}$, o estabelecimento de práticas de negociação e de troca ocorre através do trabalho como base concreta de comunicação. Coloca no cerne da questão a relação com o mercado de trabalho. N esse, estabelece parâmetros e avaliações dos riscos e benefícios entre as situações: trabalho não protegido em mercados protegidos versus trabal ho protegido em mercados não protegidos. Em relação à primeira situação, trabaIho não protegido em mercados protegidos, visualiza que esta será uma experiência mais verdadei$\mathrm{ra}$, dentro de um setting real, mas que, provavelmente, neste contexto, o paciente será admitido em um cargo protegido, com pouca remuneração, do ponto de vista da auto-estima, com os pacientes mais graves sendo excluídos do processo de seleção. N as situações em quese configurarem produção e mercado mais protegidos, os pacientes serão menos selecionados e a produção do trabaIho será maissignificativa por si mesma ecoerente.

A modernidade traz conflitos como a competitividade e a geração de empregos, provocando uma crescente exclusão do mercado de trabalho. Como então, podemos projetar trabal ho para pessoas que têm uma dificuldade de competir, uma vez que o paradigma da modernidade éa competitividade desenfreada? Ou antes, de concorrer no mercado em uma situação já em desvantagem? A superação dos obstáculos não se dará através de técnicas mais refinadas de adestramento ao trabaIho, mas sim, do enfrentamento da relação doença mental etrabalho segundo uma outra perspectiva, através de uma recomposição radical do campo ${ }^{4}$.

Estas alternativas podem se constituir em cooperativas, "lugares de promoção da autonomia bem 
como de proteção", assim como de empresas sociais. Não podemos pensar que a reabilitação psicossocial consiste no processo de adaptar os fracos ao mundo dos fortes, mas mudar as regras do jogo, para que os fortes possam compartilhar do mesmo cenário dos mais fracos ${ }^{4}$. Esta perspectiva prevê uma reestruturação do modo de a sociedade enxergar seus membros mais frágeis. Isso requer atitudes concretas que produzam possibilidades reais, e não a adoção de medidas tranqüilizadoras da boa consciência. São estes os movimentos necessários que permitem passar de uma atitude de imobilidade para a produção de sentido, de vida, de inclusão, de dignidade, de direito e justiça.

0 papel exercido pela sociedade refere-seà aceitação, ao acolhimento em relação ao portador de sofrimento psíquico. 0 papel da sociedade pode ser expresso em termos subjetivos e objetivos. 0 primeiro, anteriormente abordado, remete à dimensão afetiva com que recebe, convive eestabelece relações com os diferentes. 0 papel objetivo é a validação do primeiro, através de ações concretas que poderão trazer benefícios pal páveis à vida das pessoas, em termos de acesso ao trabalho, ao lazer, a espaços sociais, à contratualidade.

A cidadania é uma construção histórica resultante das problematizações concretas que cada sociedade produz ${ }^{8}$. Esse conceito de cidadania remete a um processo através do qual a sociedade necessita estar envolvida ativamente na luta pela emancipação de seus elementos mais frágeis, por intermé dio de sua problematização. I sso envolve uma tomada de consciência em relação aos excluídos em geral e, em particular, sobre a situação dos portadores de sofrimento psíquico. Estas transformações se dão através das pequenas lutas cotidianas que restabelecem o poder contratual aos usuários, estes movimentos conduzem a mudanças qualitativas que levem à real inserção dos portadores de transtornos mentais.

A vulnerabilidade a partir da precariedade do trabalho e da fragilidade relacional é analisada por um sociólogo ${ }^{9}$ queanalisa quea vulnerabilidadenão pode ser atribuída unicamente à dimensão econômica da crise, mas através da produção da categoria da precariedade. Para esse autor, a desagregação da integração social, para uma população que deixou de ser marginal ou residual, nasce do fenômeno da instabilidade do trabalho. Observa que a inserção relacional é menos evidenciável em virtude de não apresentar a homogeneidade que a integração pelo trabalho comporta. A ponta que o retraimento das redes familiares infligeum crescenteempobrecimento dos suportes relacionais. Situa as variáveis familiar e cultural como esteios reguladores da fragilidade relacional e da instabilidade profissional. Essas variáveis constituem o que o autor denomina de proteção aproximada.

Outro autor ${ }^{10}$, em sua análise antropológica urbana dos "territórios marginais", ressalta a importância da noção de territorialidade/desterritorialização, que se revela através da afluência das massas à cidade. Esse processo impunha um hiato, através dos cortes nos laços primários e secundários, que acabava por afrouxar as rédeas de sociabilidade. Essa fragmentação do sujeito urbano acarretava a fragmentação do ego, enquanto centralização unitária. Esta fragmentação resultante do processo de desterritorialização correspondia à perda de laços primários, familiares, domésticos, enquanto no processo dereterritorial ização recompunha-se a noção de identidade.

Evidências têm demonstrado que a história de trabalho no passado éo melhor preditivo de sucesso vocacional ou educacional. Ou seja, as pessoas que, de alguma forma, já estiveram inseridas no mercado têm mais chances de realizá-lo novamente de maneira satisfatória ${ }^{11}$. Estudos ${ }^{12}$ estabelecem uma visão global dos problemas que confrontam as pessoas com prolongadas desordens psiquiátricas e a sua experiência para entrar no mercado de trabalho. Através do entendimento da natureza e do escopo desses problemas, os reabilitadores poderão traçar intervenções estratégicas que ajudem os portadores de distúrbios mentais a al cançar sucesso na reabilitação. Dentre os problemas apontados, estão déficits de ego que desempenham um papel crítico na inabilidade das pessoas com doenças mentais crônicas para funcionarem efetivamente e manterem o emprego. A falta de auto-estima e autoconfiança, a inabilidade para tolerar frustração, o temor de falhar manifestado como baixa motivação, a ansiedade el evada ea inabilidade de ir junto com outros são apontados como fatores psicológicos que contribuem para uma reabilitação pobre. Os problemas de ordem social e vocacional são: imaturidade vocacional, manifestada através de expectativas irrealistas, falta de experiência de sucesso vocacional, inabilidade para viver independentemente, perda de adequado suporte pessoal e redesocial.

Castel ${ }^{9}$, abordando a precariedade do trabal ho e a vulnerabilidade social, traz à tona a exclusão ea desfiliação. A ponta que cada vez mais pessoas estão ficando à margem da sociedade eque a modernidade mudou o cenário e os personagens, antes centrados nos mendigos e vagabundos. A partir dos eixos da relação trabalho e da relação inserção relacional classifica zonas de espaço social de acordo com o grau de coesão entre elas. A zona de inte- 
gração, na qual estão situados os indivíduos com garantias de trabal ho permanente e sólidos suportes relacionais; a zona de vulnerabilidade, onde estão associadas precariedade do trabalho e fragilidade relacional; a zona de desfiliação, onde se encontra ausência de trabalho e isolamento social; a zona da assistência, representada pelo não-trabaIho, em razão de incapacidade versus forte inserção social. 0 cruzamento dos eixos trabalho e inserção relacional define modalidades de existência social, que vão do pólo da autonomia ao pólo de dependência ou, ainda, conforme o autor, da estabilidade à turbulência máxima.

A classificação permite situar os portadores de sofrimento psíquico em duas zonas: na zona de vulnerabilidade ena zona de desfiliação. Entendese que grande parte dos portadores de distúrbios psíquicos do país situe-se na zona de desfiliação. Esse é o grande desafio dos reabilitadores: construir redes de suporte em relação ao trabalho e à inserção relacional, através das quais se possa diminuir as fronteiras entre as zonas, considerandose que são transponíveis, porosas, não cimentadas. Esses são os movimentos necessários que levam à integração, à filiação, à inserção social.

0 perigo existequando a sociedade se resigna e aceita a precariedade e a vulnerabilidade como estados de fato ${ }^{9}$. 0 autor vê vulnerabilidade, precariedade, desfiliação, desvio, marginalidade, pobreza como processos e não como estados. Esta perspectiva permite lançar mão de instrumentos de intervenção nas situações, medidas concretas de inserção, antes do congelamento das situações em destino. Propõe como proposta uma dupla política social: uma preventiva, destinada a controlar a zona de vulnerabilidade, e outra reparadora, que teria a função de diminuir a zona de desfiliação através de intervenções concretas de inserção.

Brant e Gomez ${ }^{13}$, investigando o sofrimento de trabal hadores, gestores e profissionais da saúde de uma empresa pública de grande porte de Belo Horizonte, constataram um processo de sofrimento em adoecimento, configurado pela medicalização, somatização, psiquiatrização, licença médica, internação hospitalar eaposentadoria. Ospesquisadores entendem, diante das exigências atuais dos processos produtivos e de organização do trabalho, a necessidade do sofrimento manifestado no trabalho ser escutado e acolhido. Enquanto o mercado de produção tende cada vez mais a fragmentar, excluir, objetalizar, de outro lado, outros tendem a reconstruir, juntar os fragmentos, subjetivizar, reconstruir o ser humano na sua totalidade e complexidade. Construir e reconstruir novas formas de intervir no sofrimento, a partir da contextualização deste sujeito enquanto histórico, socialmente determinado pelo momento histórico em que vive.

A reabilitação psicossocial é vista, também, como um processo de normalização, de retorno a uma situação anterior à instalação da doença. A dificuldade de obtenção da cidadania dos que não foram "oficialmente" excluídos pelo Estado, temos os que a tiveram tutelada por décadas: a população confinada nas instituições totais. Como compatibilizar cidadania e loucura em nossa sociedade já por si excludente?

Trata-se de construir uma outra forma de a sociedade lidar com a loucura ${ }^{14}$. A desconstrução do manicômio implica a reinvenção da sociedade em que vivemos. A transformação de uma realidade histórica não poderá se dar pela técnica, mas através da revelação dos pontos de sustentação que a própria sociedade impõe. Os ideários de liberdade, igualdade e fraternidade postulados pela Revolução Francesa não são uma obviedade consensual, variam enormementeentre as sociedades eestão longe de ser hegemonicamente aceitos. 0 cidadão nasce de uma subjetividade fundada na razão. A questão paradoxal apresentada é como conciliar a reivindicação de cidadania ao louco, se este se encontra despossuído de razão. 0 autor pontua que a democracia e a concepção de cidadão não são conceitos unívocos, que são determinados pelos contextos históricos analisados. Situa que a questão da cidadania do louco encontra na construção das sociedades dificuldades em virtude de o vocabulário imprimir uma tradição racional universalista que identifica cidadania com razão. Ao entendimento da história humana como a razão sobre a não-razão prevalecerá o preconceito. Entretanto, se for visualizado como o alargamento da liberdade sobreposto à coerção, levará à solidariedade e à afirmação de valores éticos.

A convivência como cidadão na sociedadenão é o único atributo desejável. M as a convivência desprovida do preconceito que paira sobre a doença mental ainda nos dias de hoje aparece como um ideal a ser conquistado. A conquista desseideal passa necessariamente por várias instâncias, legislativa, política, de organização de serviços. Entretanto, a desmitificação da loucura precisa ser pensada não somente em termos macro, mas é a partir dos movimentos, das ações que são desenvolvidas no plano micro que se darão as mudanças mais significativas na vida dos portadores de sofrimento psíquico e estas conduzirem a saltos dialéticos que se expressam em transformações qualitativas na concretude da vida das pessoas. Dessa forma, poderá ser visualizado o desenvolvimento em espiral, que conduzirá à superação dialética. 
Apostar nas pessoas remete a acreditar na potencialidade dos portadores de distúrbios psíquicos para a mudança de padrões e comportamentos eà aquisição de habilidades que lhes permitam viver einteragir em sociedade. Este viver podedarse através da inserção real no mercado de trabaIho, como também, pelo mínimo gerenciamento o cuidado consigo mesmo, do seu tratamento, do ambiente, das suas relações interpessoais, de que for capaz. Torna-se, assim, importante "conceder crédito" às pessoas, a fim de que a sua autonomia $e$ sua capacidade possam encontrar uma ocasião de expressão e de crescimento, na convicção de que 0 verdadeiro problema é o de fazer com que consigam setornar empreendedores com respeito a si mesmos" 4 .

Alguns autores ${ }^{11}$ apontam o estigma como a maior barreira para o emprego de pessoas com de sabilidades psiquiátricas. Discutem que uma das maiores origens do estigma é a freqüente caracterização negativa das pessoas com doença mental pe los meios de comunicação demassa. A falsa caracterização dos portadores de distúrbios mentais como emocionalmente instáveis, irracionais e perigosos reflete as atitudes das pessoas leigas com os mesmos. Outra forma de estigma abordado pelos autores éo estigma sutil que reflete as crenças de os profissionais considerarem ahabilidadedas pessoas com desabilidades psiquiátricas para trabal har ou trabaIhar em qualquer atividade, mas na maioria trabaIhos domésticos. Denunciam quea forma mais insidiosa de estigma existe dentro das próprias pessoas com doenças mentais. Este estigma advém da redução do acesso a bons trabal hos e através das mensagens sutis ou abertas transmitidas pela equipe, duvidando da habilidade das pessoas para a performance no trabalho. A internalização dessas crenças negativas resulta no auto-estigma, que se revela como 0 mais duro estigma e mais difícil a ser superado.

\section{Consideraçõesfinais}

Através das considerações levantadas pelos autores, convergentes em alguns aspectos, o grande desafio imposto para a desmitificação e aceitação dos portadores de distúrbios psiquiátricos no mercado de trabalho deverá ser travado com a sociedade. Esta perspectiva necessita de múltiplas estratégias para o enfrentamento da relação loucura e cidadania, loucura e mercado de trabalho.
Estes movimentos, sal tos dialéticos, remetem a uma sociedade que inclua, acolha, estabeleça valores humanos pautados na ética com os mais frágeis.

A reforma psiquiátrica introduziu no campo a noção decidadania dos doentes mentais. Dessa forma, as ações coerentemente deverão ser centradas na busca dessa cidadania pelos profissionais e usuários. Este conceito de cidadania poderá se dar em termos de produção, como também em termos da qualidade de vida alcançada com o processo reabilitativo, mas, sobretudo, quando as pessoas se reconhecerem como sujeitos históricos que podem intervir para mudar a realidade. 0 diferencial entre produção de vida e vida produtiva deve ser considerado. Da cidadania francamente tutelada à cidadania emancipada sobrepõem-se desafios éticos que deverão ser respondidos pela construção de uma sociedade mais tolerante, em que a possibilidade venha substituir a centralização na razão.

É necessário apreender a complexidade do processo, no momento em que um conjunto de variáveis são colocadas em campo. Às respostas a essas variáveis necessitam corresponder intervenções em várias áreas: casa, família, trabalho, rede social. Para alcançar este grau de reabilitação, diversos eixos precisam ser trabalhados: 0 eixo casa, trabalho, família e rede social. De todos os eixos citados, 0 trabalho se revela como um dos pontos frágeis e difíceis de ser operacionalizado. Principalmente o trabalho formal, que requer a inserção no mercado de trabalho extremamente competitivo. Alternativas que remetam à inserção no mercado e possam dar conta do vácuo trabalho na vida dos portadores de distúrbios mentais necessitam ser estudadas. Essas alternativas poderão vir desetores empresariais mais comprometidos com a questão social, através do estabelecimento de parcerias. N estas parcerias, não poderá faltar o suporte dos profissionais, tanto aos usuários como aos empregadores.

Neste sentido, deverão ser realizados movimentos que contemplem a complexidade e as demandas particulares de cada pessoa. Isso remete ao estabelecimento de práticas dinâmicas num constante processo de reconstrução/superação, no qual são produzidas possibilidades sempre novas e plurais. A estagnação resulta em institucionalismo, cronicidade. Fazer as pessoas tornarem-se empreendedoras e sujeitos da própria história deverá se constituir, por excelência, num compromisso primordial assumido pelos reabilitadores. 


\section{Referências}

1. Rotelli F, De Leonardis O, Mauri D. Desinstitucionalização. 2ª ed. São Paulo: Hucitec; 2001.

2. Bertolote JM. Em busca de uma identidade para a reabilitação psicossocial. In: Pitta A. organizadora. Reabilitação psicossocial no Brasil. São Paulo: Hucitec; 1996. p. 155-158.

3. Silva JF Filho. Um outro modo de olhar. In: Pitta A. organizadora. Reabilitação psicossocial no Brasil. São Paulo: Hucitec; 1996. p. 60-62.

4. Saraceno B. Libertando identidades: da reabilitação psicossocial à cidadania possível. Rio de Janeiro: Instituto Franco Basaglia/Te Cora; 1999.

5. Pitta A. organizadora. Reabilitação psicossocial no Brasil. São Paulo: Hucitec; 1996.

6. Demo P. Cidadania tutelada e cidadania assistida. São Paulo: Autores Associados; 1995.

7. Cohen LJ. Work and mental health. Soc Psychiatry Psychiatr Epidemiol 1990; 25:108-113.

8. Brasil. Ministério da Saúde. Relatório final da 2a Conferência Nacional de Saúde M ental. Brasília: M inistério da Saúde; 1994.

9. Castel R. Da Indigência à exclusão, a desfiliação: precariedade do trabal ho e vulnerabilidade relacional. In: Lancetti A, organizador. Saúde Loucura 4. São Paulo: Hucitec; 1994. p. 22-48.

10. Perlonguer N. Territórios marginais. In: Lancetti $A$, organizador. Saúde Loucura 4. São Paulo: Hucitec; 1994. p. 49-69.

11. Pratt W, Gil KJ, Barret NM, Roberts MM. Psychiatric rehabilitation. London: Academic Express; 1999.

12. Jansen MA. The psychological and vocational problems of persons with chronic mental illness. In: Ciardello JA, Bell MD, editors. Vocational rehabilitation of persons with prolonged psychiatric disorders. Second printing. London: The Johns Hopkins Press Ltd.; 1991. p. 35-46.

13. Brant LC, Gomez CM. O sofrimento e seus destinos na gestão do trabalho. Cien Saude Colet. [periódico na Internet]. 2005; 10(4): [cerca de 14 p]. [acessado 2006 mar 21]. Disponível em: http://www.scielo.br/ scielo.php

14. Bezerra B Jr. Cidadania e loucura: um paradoxo? In: Bezerra B Jr, Amarante P, organizadores. Psiquiatria sem hospício: contribuições ao estudo da reforma psiquiátrica. Rio de Janeiro: Relume-Dumará; 1992. p. 13-26.

Artigo apresentado em 21/03/2006

Aprovado em 13/12/2006

Versão final apresentada em 04/01/2007 